\title{
Properties of Granular Materials as Heat Transfer and Storage Medium in CSP application
}

\section{T. Baumann, S. Zunft}

Institute of Technical Thermodynamics, German Aerospace Center, Pfaffenwaldring 38-40, 70569 Stuttgart, Germany, Phone: 49-711-6862432, Fax: 49-711-6862747, E-mail: torsten.baumann@dlr.de

\begin{abstract}
A selection of granular natural and ceramic materials have been experimentally characterized with regard to their application as heat transfer and storage media in concentrating solar power plants. Thermophysical, thermomechanical, tribological and rheological measurements have been conducted in order to identify the most suitable candidates for this dynamic high temperature operation. Ceramic materials are found to comprise some advantages, but natural products offer a considerably more economical solution. Thermal bulk conductivity is found to be only marginally affected by the solid's conductivity, while specific heat is almost the same for all solids. Ceramics entirely withstand thermal cycling, while quartz-containing materials are prone to severe degradation. Most materials are found to attain a saturated state of attrition while being sheared under load, wherein quartz sand offers the lowest mass fraction of debris at saturation level. In the investigated grain size range, all materials show excellent flowability. The generation of debris requires consideration in the design of the CSP storage components.
\end{abstract}

Keywords: granular material; CSP; thermal energy storage; moving bed; heat exchanger

\section{Introduction}

In solar thermal power plants, electricity is generated from concentrated solar energy driving a conventional power cycle. A thermal energy storage (TES) system is necessary to ensure the dispatchability of this technology since the solar irradiation depends on the weather, annual seasons, as well as day and night cycles. Regarding the current state-of-the-art, further efforts have to be made regarding the cost-effectiveness and simplicity of those systems to evolve concentrated solar power (CSP) technology that is competitive with fossil power plants. One promising approach is the application of fine-grained particulate materials as the storage and heat transfer medium in Central Receiver Systems (CRS). As an advantage, granular materials allow for high process temperatures in CSP systems $\left(>600^{\circ} \mathrm{C}\right)$ and can be used both as heat transfer and heat storage media, which offer higher power plant efficiencies and also a potential cost reduction in comparison to molten salt, which is today's most common heat transfer fluid used in CSP [1] .

Recent concepts involve making use of direct particle receivers [2] or applying hot air from volumetric receivers in an air-particle heat exchanger [3] to heat up the particulate material. The solar heated material can then be stored in a storage containment and be discharged whenever the energy is needed. A promising technology option for the thermal discharge is the moving bed heat exchanger (MBHX) [4]. The transport of the granular bulk within the CSP system can, for example, be provided by bucket or belt conveyors.

In a CRS system, as shown in Fig. 1, the inventory material has to meet a variety of requirements to provide a long life cycle of both the material and the enclosing system. The material has to be resistant to high temperatures and also high temperature gradients, since it is used at temperatures up to $1000^{\circ} \mathrm{C}$ and undergoes cyclic thermal loads due to charging and discharging. To extract the heat, good thermophysical properties are desirable, such as high thermal bulk conductivity and high heat capacity. Since the particles are exposed to attrition and may also generate abrasive wear in the system's components, the tribological behaviour is of great interest. Since the bulk is going to be used as a heat transfer medium, the flow behaviour also has to be considered.

Some highly available natural products can be an attractive low cost option, while more cost-intensive ceramics may offer advantages due to better thermophysical or optical properties. To identify suitable materials that can be applied for CRS storage systems, a variety of granular products are characterized experimentally regarding some crucial thermophysical, thermomechanical, tribological and rheological properties. The investigations include natural stones as well as technical ceramics with a mean grain size between $0.5 \mathrm{~mm}$ and $3.0 \mathrm{~mm}$. 


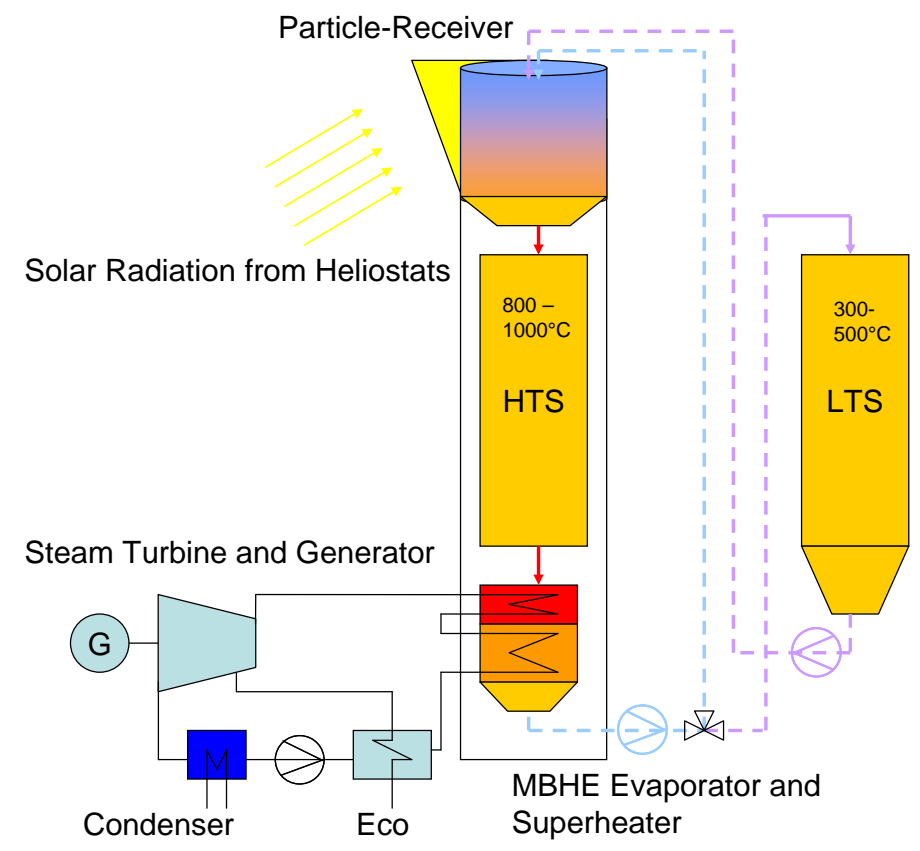

Fig. 1.

\section{Experimental details}

In the following, the main criteria for the material selection are identified. Subsequently, suitable available products are selected for further investigation.

Afterwards, the different measurement methods as well as the results for characterization of the thermophysical, thermomechanical, tribological and rheological properties are presented.

\subsection{Selection of short-listed materials}

Materials used as inventory material for solar power plants have to fulfil certain requirements. Most available materials are limited to a maximum application temperature. In the receiver and the storage, material temperatures of $1000^{\circ} \mathrm{C}$ can easily be reached, thus the short-list of materials is limited to inorganic-nonmetallic materials like some natural stones or ceramics. Those materials offer thermal stability to temperatures well over $1000^{\circ} \mathrm{C}[5,6,7,8]$.

A first attempt to characterize materials for particle receiver applications was conducted by Sandia National Laboratories in the 1980s $[9,10]$ These experiments concentrated mainly on the optical properties of granular materials regarding the solar absorption in a solar direct receiver. Also, the sintering resistance as well as the shape and the surface of sintered bauxite and fused zircon grains were characterized. Falcone et al. [11] identified silicon carbide, aluminium mixtures, quartz sand and silicon glass as suitable materials for a solar CRS. The works of Py et al. [12] and Tayeb [13] studied the suitability of low-cost waste and recycled ceramic materials for CSP application but did not consider particulate media.

Not all potential candidate materials are commercially available, while some others are too expensive to be manufactured in sufficient quantity or are considered toxic. The available grain size limits the selection, since not all candidates are available as fractionized granular bulk in the desired grain size range.

To achieve an adequate balance between good handling properties and sufficient flowability of the bulk, a desired grain size range from 0.5 to $3.0 \mathrm{~mm}$ is considered sufficient. The materials selected for further testing are summarized in Table 1. For sintered bauxite, alumina, quartz sand and corundum, batches with two different mean grain sizes were tested, as can be seen from Table 1. 
Table 1. Geometric properties of tested granular materials

\begin{tabular}{ccccc}
\hline Material & $\begin{array}{c}\text { Volumetric mean grain size } \\
{[\mathbf{m m}]}\end{array}$ & $\begin{array}{c}\text { Standard deviation } \\
{[\mathbf{m m}]}\end{array}$ & $\begin{array}{c}\text { Shape factor } \\
{[-]}\end{array}$ & $\begin{array}{c}\text { Bulk } \\
\text { porosity } \\
{[-]}\end{array}$ \\
\hline Sintered bauxite & 1.49 & \pm 0.26 & 1.08 & 0.48 \\
& 0.56 & \pm 0.09 & 1.09 & 0.48 \\
Alumina grinding balls & 2.01 & \pm 0.50 & 1.07 & 0.41 \\
& 1.17 & \pm 0.20 & 1.06 & 0.42 \\
Basalt & 2.89 & \pm 1.08 & 1.21 & 0.47 \\
Quartz flint & 2.02 & \pm 0.57 & 1.14 & 0.44 \\
Quartz sand & 0.80 & \pm 0.18 & 1.15 & 0.44 \\
Normal corundum & 1.83 & \pm 0.42 & 1.22 & 0.50 \\
& 1.61 & \pm 0.36 & 1.22 & 0.51 \\
Silicon-carbide pearls & 1.13 & \pm 0.35 & 1.14 & 0.35 \\
\hline
\end{tabular}

\subsection{Measurement methods}

\section{Grain size distribution and shape factor}

The grain size is determined by the image analysis measurement system PowderShape by IST [15]. To characterize the geometric properties of a bulk, a representative sample is prepared on a transparent, adhesive substrate. A digital image of the specimen's projection is taken by an optical scanner. The analysis with the PowderShape software allows us to determine, amongst other things, the mean grain size representing the mean diameter, the grain size distribution and the shape factor.

The grain size of one particle is defined as the diameter of a circle $d_{c}$ with the same surface area as the filled shape of the particle. The volumetric mean grain size $d_{p, \text { mean }}$ is thus defined as

$d_{p, \text { mean }}=\left(\sum_{i=1}^{n} \frac{d_{p, i} V_{p, i}}{\bar{V}_{p}}\right) n^{-1}$,

where $d_{p, i}$ is the individual particle diameter, $V_{p, i}$ the resulting volume of the corresponding sphere, $\bar{V}_{p}$ is the mean volume and $n$ the number of counted particles on the substrate.

The shape factor makes a statement about the particle's sphericity and is defined as

$f_{p, i}=\frac{C_{p, i}}{C_{c, i}}$,

where $C_{p}$ is the particle's circumference and $C_{c}$ is the circumference of a circle having the same surface area as the particle. Values of 1.0 for perfectly round objects (spheres) and 1.25 for irregularly shaped particles represent the two extremes. The mean value of the representative sample is determined by

$$
f_{p, \text { mean }}=\left(\sum_{i=1}^{n} f_{p, i}\right) n^{-1} \text {. }
$$

The initial grain sizes, including standard deviation as well as the shape factor, are given in Table 1. The porosity of the randomly poured bulks is defined as

$\varepsilon_{f}=\frac{\rho_{S O}-\rho_{s}}{\rho_{f}-\rho_{S}}$ 
and is also given in Table 1 .

\section{Thermal conductivity}

The thermal conductivity of the bulk is one of the determining factors for the thermal performance of a heat exchanger for thermal charging or discharging of the bulk [16]. Knowledge of this bulk parameter is therefore crucial for its design.

Measurements of the effective thermal bulk conductivity were performed by applying the hot wire method in a Netzsch TCT 426 thermal conductivity analyzer (see Figure 3). A strained platinum wire runs through the bulk and acts as a heat source and a temperature sensor. Thermal conductivity is determined as a time-dependent function of the temperature change at a constant heat flux. The bulk conductivity was measured in a temperature range from room temperature to $800^{\circ} \mathrm{C}$ for the materials listed in Table 1 .

\section{Specific heat}

Another influential parameter for the thermal behaviour of the bulk is the specific heat. For storage application, a high density and a high specific heat are desirable to achieve a high heat capacity of the storage and also the heat transfer in a moving bed is positively affected by a high $c_{p}$ value [15].

The specific heat is a material parameter normalized by weight. Since the density of interstitial gas (e.g. air) is at least three magnitudes smaller than the solid's density, a randomly packed bulk's specific heat is regarded as equal to the solid. This parameter can be found in literature for most of the regarded materials in various temperature ranges, e.g. in VDI Wärmeatlas [16], or is given by the manufacturer.

To investigate the actual temperature dependency, the specific heat of quartz sand and sintered bauxite is measured. Measurements are conducted using a Netzsch DSC 404, applying the method of differential scanning calorimetry (DSC). The previously pulverized material of interest and a reference specimen are each filled into a crucible which is operated inside the adiabatic, argon-filled environment of the device and exposed to a controlled temperature program. The specific heat is a time-dependent function of the specimen's temperature and the temperature difference evolving between the specimen and the reference material.

\section{Thermal shock}

To ensure stable and predictable operating conditions of the particle-based CSP system over the material's lifetime, degradation and the resulting variation of grain size distribution must be avoided or at least be predictable, as this would increase pressure drop (e.g. in an air-particle heat exchanger or a fluidized bed) and may affect the flow behaviour of the bulk. One of the potential origins of such structural failures is thermal shock, which might, for instance, occur in the receiver or in the heat exchanger during heating or cooling operations, respectively, and must therefore be considered.

Temperature gradients may cause thermally induced stresses in the grain due to thermal expansion of the material. Since the tensile strength for most materials is some orders of magnitude lower than the compressive strength, induced tensile stresses are more critical to the grain's integrity than compression. Internal tensile stress in the outer layer of the grain can be induced by cooling. The higher the temperature gradient inside the grain, the higher the internal stresses. To that end, thermal cycling was performed with the focus on a high cooling rate. The tests were applied to the materials through heating to approx. $810^{\circ} \mathrm{C}$ in a batch furnace, water quenching at $20^{\circ} \mathrm{C}$ and subsequent drying at $110^{\circ} \mathrm{C}$. With the help of the image analysis system PowderShape, grain size distribution was determined after at least 30 cycles and then compared to the initial distribution of the untreated specimens. Also, the alteration of the grain shape was analysed.

\section{Attrition}

The relative movement of the particles in a dense granular bulk is another origin of potential breakage and thus of changes in grain size distribution. In order to estimate this behaviour for the different granular products, attrition tests were performed in a ring shear cell, as shown in Figure 2 below.

The device consists of a ring channel filled with the granular material and a matching cover plate made of hardened steel with a smooth surface. During tests, the bulk material is consolidated by the plate with a specified normal force, inducing a normal stress $\sigma$ in the bulk. By rotation of the cover plate, additional shear stress $\tau$ is generated (see Figure 2, right hand side). A perforated plate is installed at the bottom of the ring channel, 
keeping the lower layer of particles in place to achieve the formation of a shear zone within the bulk of 20-30 mm width.

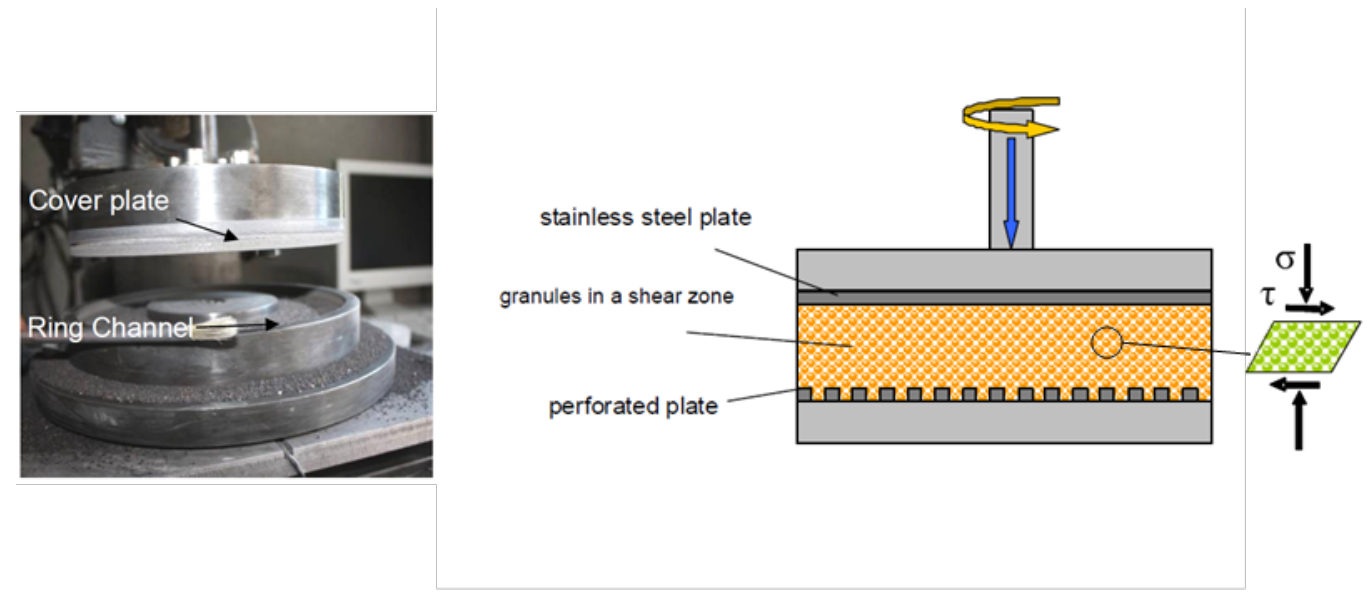

Fig. 2.

The failure zone, in which attrition occurs due to friction and collisions between the particles caused by a high strain rate, is assumed to have a width of 6 to 10 times the particle diameter $[17,18]$. An initial mean grain size of the specimens ranging from 1.5 to $2.9 \mathrm{~mm}$ implies that the failure zone is fully developed inside the generated shear zone. All tests have been conducted with a normal force of $2 \mathrm{kN}$, inducing a normal stress of $84 \mathrm{kPa}$ in the bulk. The rotational speed of $42 \mathrm{rpm}$ corresponds to a mean peripheral velocity of $3 \mathrm{~m} / \mathrm{s}$. According to the Janssen equation (e.g. as explained in [18]), the stress would comply with a maximum wall stress in a hopper with $8 \mathrm{~m}$ diameter and a wall friction angle of $20^{\circ}$, as is the case for a combination of bauxite and smooth steel. For materials available in different mean grain sizes (alumina balls, sintered bauxite, quartz sand and normal corundum), only the batches including the larger grains are used for the tests.

Attrition is defined as the mass fraction of particles smaller than their smallest initial grain size. Since a quantified classification of the mass fraction is necessary to determine attrition, sieve analysis is preferred over the optical PowderShape method. For sieve analysis, approximately $40-100 \mathrm{~g}$ of the attrited specimen were given onto a vibrating sieve stack consisting of 6 sieves of different mesh sizes $(1.8 \mathrm{~mm} ; 1.4 \mathrm{~mm} ; 0.8 \mathrm{~mm} ; 0.63$ $\mathrm{mm} ; 0.4 \mathrm{~mm} ; 0.315 \mathrm{~mm}$ ) and a ground plate. After being shaken for 5 to 10 minutes, the remaining fraction on each sieve (including the ground plate) was weighed.

\section{Rheological properties}

The knowledge of rheological properties is essential to estimate the flow behaviour of the bulk flowing through hoppers or chutes and thus for designing storage systems or heat exchanger devices. They provide crucial information on the critical dimension of the outlet width to prevent arching.

Rheological measurements have been conducted using the ring shear cell Powder Flow Tester and the software Powder Flow Pro, both by Brookfield Engineering Labs. The principles of a ring shear cell are described in various works (e.g. $[17,18])$. In the shear cell, the bulk is confined and subsequently sheared, while both the normal and the shear stresses are directly measured. By doing so, the so-called flow function is determined. This measuring technique also allows us to determine other rheological parameters like the inner friction angle or bulk density. From the measurements, critical design parameters for the design of the storage containment and the heat exchanger can be computed.

\section{Results and Discussion}

\subsection{Thermophysical properties}

\section{Thermal Conductivity}

In Figure 4 below, the results of the thermal bulk conductivity measurements are shown. The general increase of effective conductivity with temperature is attributed to the increasing contribution of thermal radiation at higher 
temperatures. As can be seen from the diagram in Figure 4, a larger grain size of the same material leads to a higher effective conductivity. Here, the underlying effect is seen in the reduced number of particle-particle contacts reducing the thermal resistance for larger particles. Also, the radiative resistance is reduced with a smaller number of particles on a given distance. Bulks consisting of irregularly shaped particles demonstrate a slightly more progressive increase of conductivity with temperature than spherical particles (e.g. corundum or quartz sand). The emitting surfaces of two adjacent, non-spherical particles are more closely spaced, leading to an increased heat transfer due to radiation in the bulk at elevated temperatures.

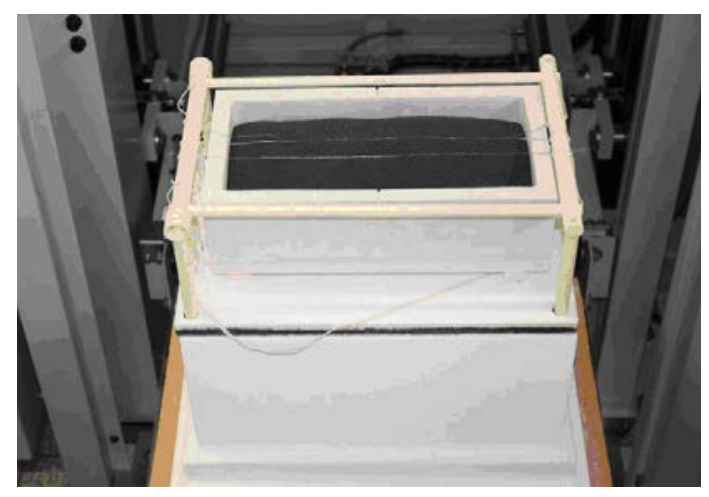

Fig. 3.

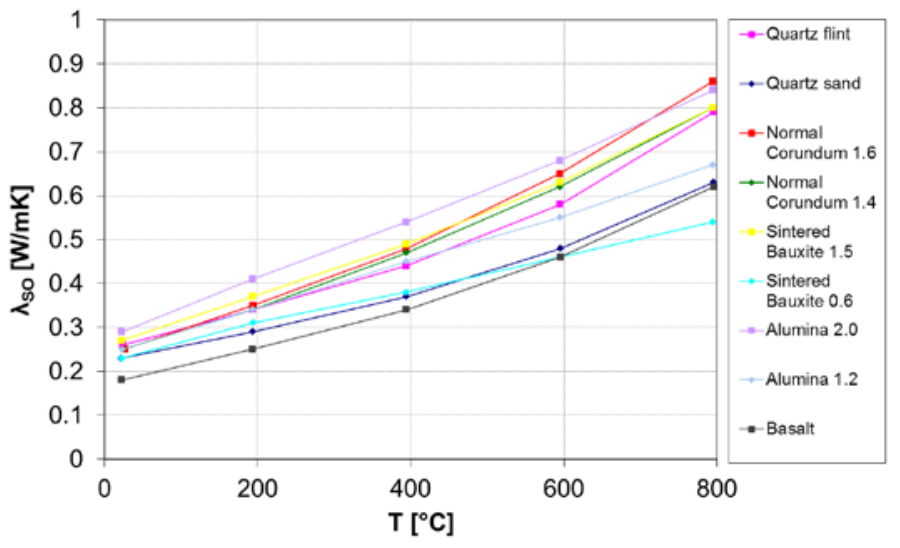

Fig. 4.

An empirical model to estimate the thermal bulk conductivity is given by Zehner and Schlünder [19]. In their unit cell model, they describe the heat conduction in the bulk as parallel paths of heat flux through the fluid phase and a mixture of both phases. The parameters needed for the computation are the molecular conductivities of the participating phases, the mean diameter and the porosity. The latter can be taken from the hot-wire measurements, since the mass and volume of the specimen are known. Empirical parameters depending on material and shape are included in the model. The exact formulation of the model can be found in [19].

Applying the Zehner and Schlünder model, the bulk conductivities for quartz and bauxite were calculated and are plotted over temperature in Fig. 5 alongside the experimental results. As can be seen from Figure 5, the calculated conductivities are in good agreement with the measured results. For sintered bauxite, only values for temperatures from $400^{\circ} \mathrm{C}$ are shown, since no thermal conductivity for the solid is given for lower temperatures [16]. The molecular conductivities for quartz are taken from Colosky [20] and Birch [21].

Since the model provides reliable results, it is considered suitable to predict bulk conductivities at higher temperatures than the measured ones or for materials that cannot be characterized using the hot wire device. This is in fact the case for $\mathrm{SiC}$ products like SiC-pearls, since the carbon is expected to react with the platinum-made wire of the testing device at elevated temperatures. Thus, the bulk conductivity of SiC pearls is only measured for room temperature and determined for higher temperatures using the Zehner-Schlünder model as shown in Figure 6. The results show that $\mathrm{SiC}$ offers the highest thermal conductivity of all the tested materials. It exceeds quartz by approximately $95 \%$ at room temperature and $50 \%$ at $800^{\circ} \mathrm{C}$. This is caused by its relatively high molecular conductivity as well as its very low bulk porosity.

The results indicate that the molecular conductivity has only a small influence on the bulk conductivity. Only a significant increase of the solid's conductivity positively affects the bulk conductivity. Thus, the molecular conductivity can be regarded as a minor selection criterion for CSP application. Nevertheless, a high grain size as well as low bulk porosity leads to increased conductivity, as can also be represented by the model of Zehner and Schlünder. 


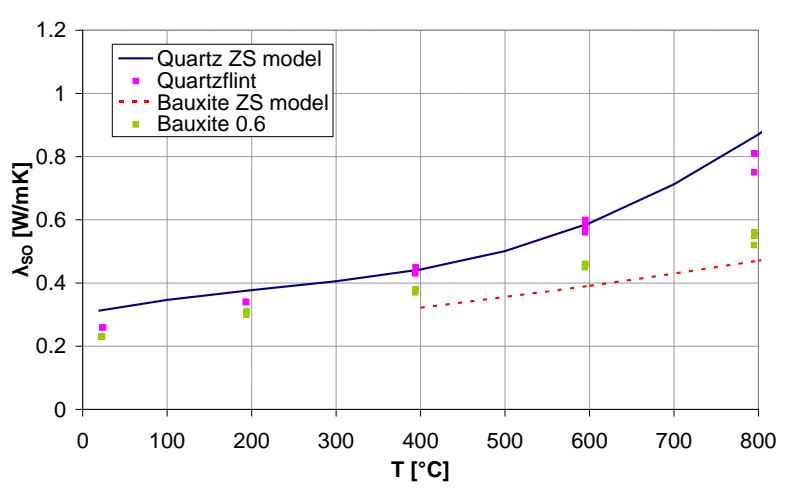

Fig. 5.

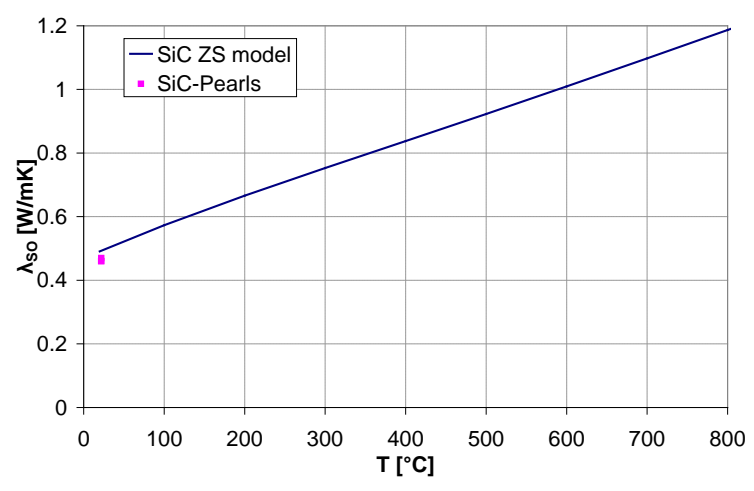

Fig. 6 .

\section{Specific heat}

The results of the temperature-dependent specific heat measurements for quartz sand and sintered bauxite are shown in Fig. 7. The specific heat increases with temperature for both materials, starting at approximately $850 \mathrm{~J} / \mathrm{kgK}$ at room temperature. For quartz sand, $c_{p}$ increases more significantly. At $600^{\circ} \mathrm{C}$, the values of $c_{p}$ for quartz sand and bauxite are $1187 \mathrm{~J} / \mathrm{kgK}$ and $1121 \mathrm{~J} / \mathrm{kgK}$, respectively.

In [16], the specific heats for a variety of materials are given for specific temperature ranges. For bauxite, a value of $1045 \mathrm{~J} / \mathrm{kgK}$ is announced for a range of $20^{\circ} \mathrm{C}$ to $600^{\circ} \mathrm{C}$, which corresponds very well to the mean value of $995 \mathrm{~J} / \mathrm{kgK}$ from the measurements (realized from $45^{\circ} \mathrm{C}-600^{\circ} \mathrm{C}$ ). $\mathrm{For}^{\mathrm{SiO}} \mathrm{S}_{2}$, a mean specific heat of around $945 \mathrm{~J} / \mathrm{kgK}$ is given for the mentioned temperature range (determined from [22]). The measured mean value for quartz sand is $1062 \mathrm{~J} / \mathrm{kgK}$. The difference between these values may be caused by inhomogeneous composition of the phases in the grains. Hence, quartz sand cannot be regarded as pure $\mathrm{SiO}_{2}$ with a homogeneous quartz phase.

The sudden peak at $573^{\circ} \mathrm{C}$ for quartz sand is caused by the quartz inversion and thus recrystallization. At this point, a rapid increase of the specific volume occurs due to the transition from $\alpha$ - to $\beta$-quartz $[23,24]$. Above the transition temperature, the specific heat rapidly decreases to a stable value close to that of sintered bauxite (see Fig. 7).

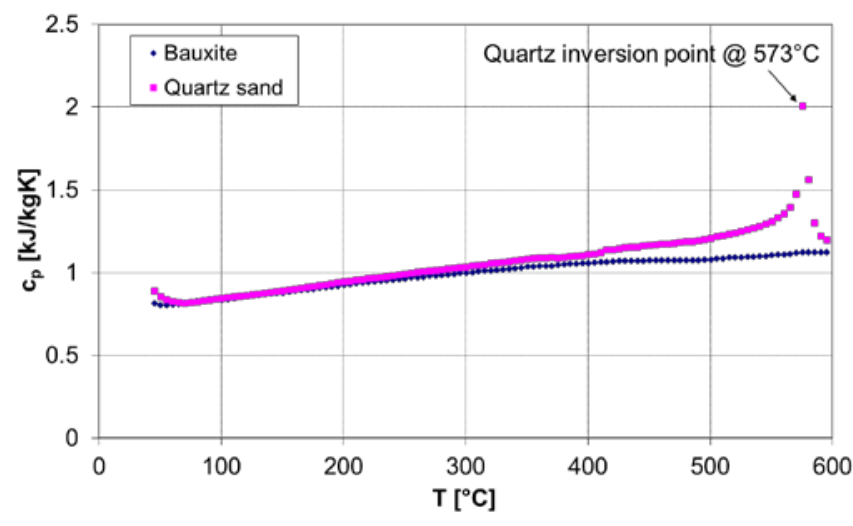

Fig. 7.

\subsection{Thermomechanical properties}

\section{Thermal shock resistance}

In the following, the results of the thermal cycling tests are presented and discussed. It turns out that for the ceramic materials, like sintered bauxite or alumina, the grain size distribution remains unaffected by this treatment. This is illustrated through the almost unchanged grain size distribution in Figures 8 and 9 for alumina 
and sintered bauxite, which indicates a high lifetime expectancy with cyclic thermal loads. ${ }^{1}$

From analysis of the shape factor (shown in Fig. 12), it can be seen that not only is the grain size distribution of the ceramic materials unaffected by thermal shock. Also, the grains did not undergo any change of shape, which underlines the observed resistance to thermal shock.

For basalt and corundum, the shape factor is not a representative parameter to evaluate degradation, since the grains are already irregularly shaped initially. Breakage of these grains would result in an increased fraction of small particles, but the shape factor will remain almost constant.

In contrast to the ceramic materials, the investigated natural products show a higher sensitivity to thermal cycling. As can be seen from Figure 11, quartz shows a pronounced granular disintegration, becoming visible from an increased fraction of fine particles after 30 cycles, along with a decreased fraction of larger grains. A significant increase of the shape factor is determined, resulting from a change of the grain's shape due to chipping and fractioning of the grains. The thermally-induced internal stress is further amplified by the quartz inversion that occurs at approximately $573^{\circ} \mathrm{C}$, at which the specific volume of the quartz phase increases by 0.8 $\%$ and leads to additional mechanical stress inside the non-isothermal particles. If the stress exceeds the tensile strength of the material, breakage of the grains occurs.

Less pronounced but still visible effects of degradation have been determined for basalt (see Fig. 10) and normal corundum. A possible breakage mechanism could result from a typically existing quartz phase in those grains. A second argument for the instability of basalt is found in the low theoretically determined critical temperature gradient. In Schulle [25] the maximum cooling rate is defined by

$\left(\frac{d T}{d t}\right)_{\max }=\frac{\sigma_{t}(1-v)}{\alpha E} \frac{\lambda}{c_{p} \rho} \frac{1}{l^{2}}$.

The material's tensile stress $\sigma_{t}$, Young's modulus E, Poisson's number $v$, density $\rho$ and thermal conductivity $\lambda$ of the solid can be taken from literature. The sample length in the direction of the temperature gradient $l$ is presumably half the particle diameter, which is known from measurements. The heat transfer coefficient of water to particle $\alpha$ can be determined using a suitable Nusselt correlation, e.g. the correlation proposed by Gunn [26].

The computed maximum cooling rate and the actual cooling rate from the experiments are shown in Figure 13 for basalt and quartz sand. As can be seen from the diagram, only the theoretical cooling rate for the basalt grains has been exceeded in the experiments. There are uncertainties in the prediction of the Nusselt number (which is related to spherical particles) and material parameters may vary in consequence of inhomogeneous phase compositions. Nevertheless, these values provide an explanation for the degradation of the natural products, at least for basalt. The instability of basalt results from a high coefficient of thermal expansion [5] and low thermal conductivity [27]. The correlation does not take into account any recrystallisation processes or phase changes like the quartz inversion. Thus, the degradation of quartz is probably due solely to the quartz inversion, since its theoretical cooling rate has not been exceeded.

An additional 30 cyclic tests for quartz sand without water quenching showed that no measurable degradation of the grains occurs with a heating rate of $25 \mathrm{~K} / \mathrm{min}$ and a cooling rate of $4 \mathrm{~K} / \mathrm{min}$ in a narrow temperature range around the quartz inversion temperature of $573^{\circ} \mathrm{C}$.

Concluding, the use of natural products containing quartz phases in general, and specifically quartz products, bears the risk of degradation when operated with high temperature gradients around the quartz inversion point.

\footnotetext{
${ }^{1}$ The minimal drift between the grain size distribution curves is caused by uncertainties of the measurement method: none of the product's grain size distributions are homogeneous, and the number of grains on each substrate is limited. Each specimen of one material at one state of degradation is unique and not exactly reproducible.
} 


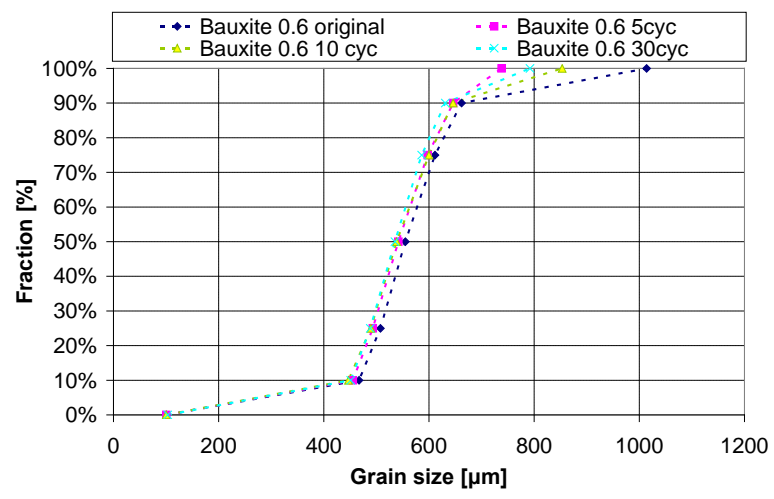

Fig. 8.

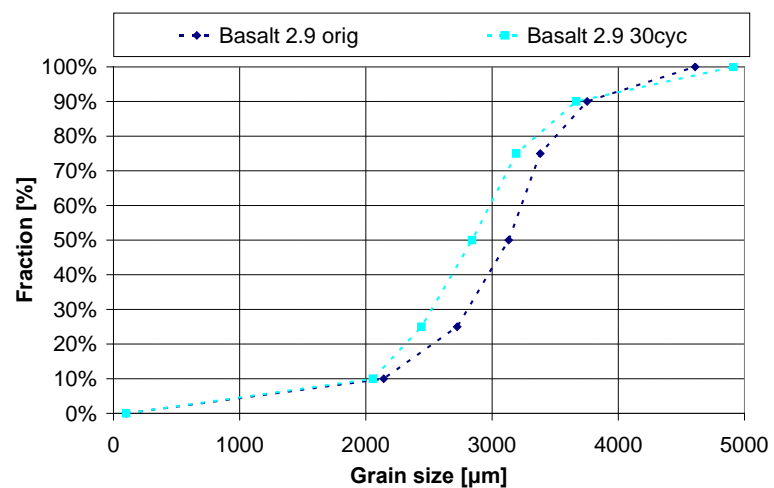

Fig. 10.

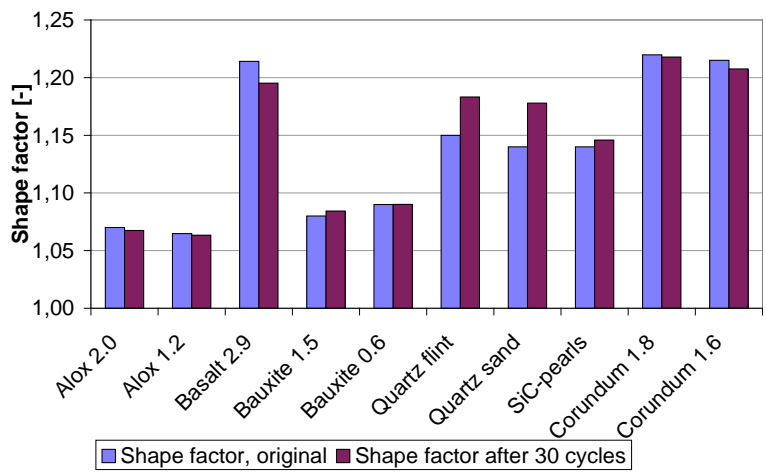

Fig. 12.

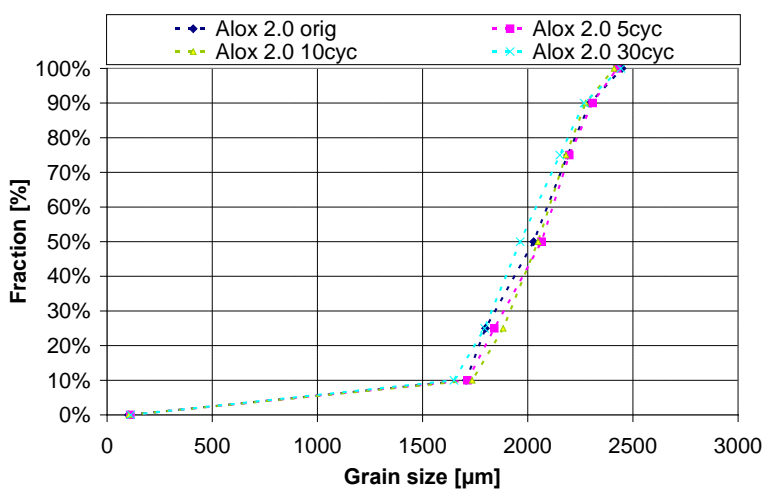

Fig. 9.

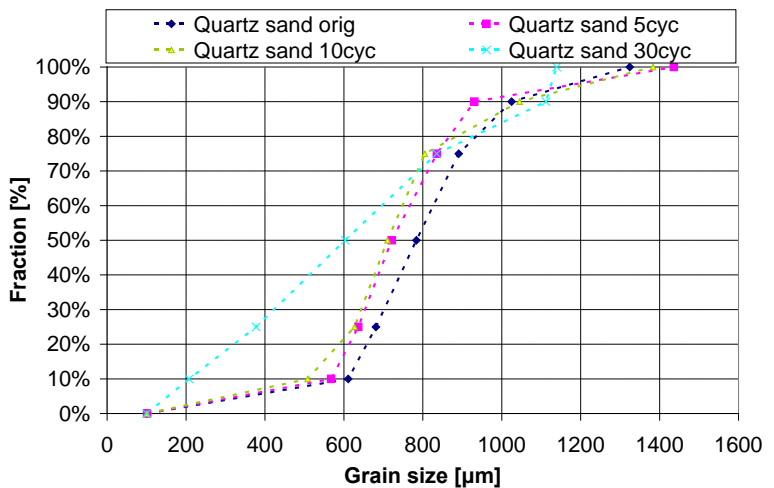

Fig. 11.

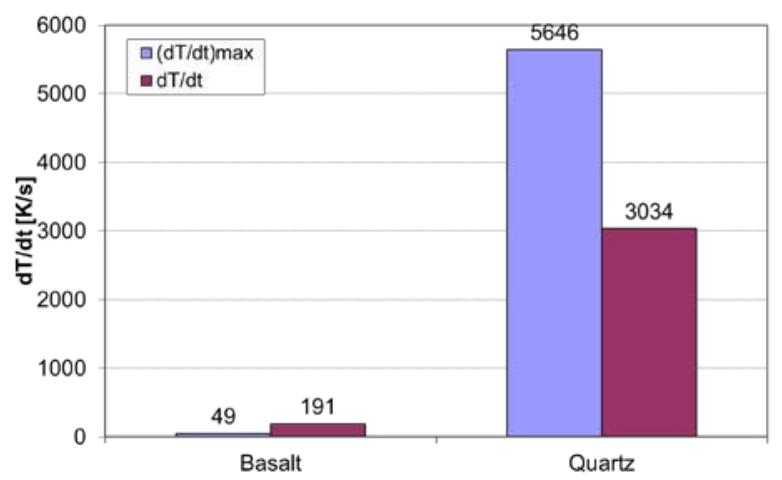

Fig. 13.

\subsection{Attrition behaviour}

The test results of the sieve analysis after the bulks have been exposed to attrition are summarized in Fig. 14. The mass fraction of attrition is plotted versus the strain rate, which is defined as the ratio of shear length to sample layer thickness. It can be gathered that, unlike all the other tested materials, alumina grinding balls turn out to remain completely wear-free thanks to their high attrition resistivity: a high roundness, a hardness twice as high as that of quartz and a compressive strength and Young's modulus approximately ten times higher than for basalt [6,7]. Quartz shows the lowest attrition rate of all the tested materials. Bauxite degrades faster than quartz flint, but the two materials' attrition saturates at a value of around $60 \%$ and $45 \%$, respectively. No such saturation effects were observed for corundum and basalt within the indicated testing periods: while corundum's attrition tends to saturate beyond $90 \%$, the attrition of basalt increases progressively with shear strain. 
Nevertheless, the attrition of basalt is the lowest of all the tested materials within the period of examination.

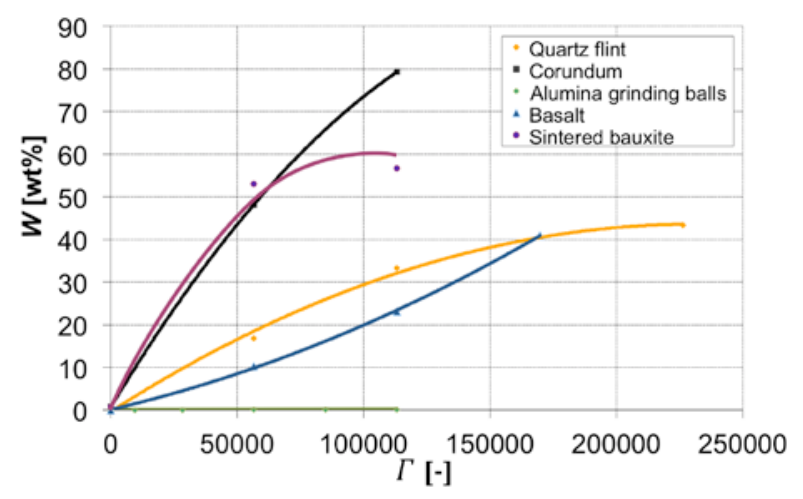

Fig. 14.

The quantitative analysis can now be used to deduce statements on the long-term behaviour of the materials: Based on the modified Gwyn equation by Neil and Bridgwater [28,17], an empirical correlation, the particle attrition can be related to the mechanical load condition expressed by the bulk's normal stress and shear strain:

$$
W=K_{N}\left(\frac{\sigma \Gamma^{\phi}}{\sigma_{t}}\right)^{\beta} .
$$

Herein, $W$ is the mass fraction of broken particles, $\Gamma$ the shear strain, $\sigma$ the normal stress applied to the bulk and $\sigma_{t}$ the tensile strength of the solids. Performing least square fits on the experimental data by applying Equation 6 allows us to estimate the material parameters $\beta, \Phi$, and $K_{N}$. The parameters $\beta$ and $\Phi$ are measures for the influence of stress and strain on attrition, respectively. $K_{N}$ can be interpreted as a measure of attrition at a shear strain of unity and is called the Gwyn constant [28]. The identified values of $\beta, \Phi$ and $K_{N}$ are listed in Table 2 . Note that these values are valid for the presented case of a bulk which is in contact with a smooth surface. The shear strain is thus related to the relative velocity of the steady wall to the core velocity of the bulk.

Table 2. Material parameters for the modified Gwyn equation

\begin{tabular}{cccc}
\hline Material & $\mathbf{B}[-]$ & $\mathbf{\Phi}[-]$ & $\mathbf{K}_{\mathrm{N}}[-]$ \\
\hline Sintered bauxite & 0.3 & 1.0 & 0.48 \\
Basalt & 2.7 & 0.5 & 135 \\
Alumina & 0.4 & 0.05 & 0.035 \\
Normal corundum & 1.45 & 0.5 & 1.79 \\
Quartz flints & 1.05 & 0.5 & 1.13
\end{tabular}

Equation 6 can be applied to gain crucial information on the material's attrition behaviour, assuming the load conditions are known (e.g. stresses and shear strain inside the device). As can be seen from Equation 6, attrition is a function of the stress $\sigma$ (vertical stress on the wall) and the width of the shear zone. As an example, for a given shear length and a specified flow velocity, the influence of the shear zone width is shown in Figure 15 as a function of normal stress for sintered bauxite. Independently of the induced stress, attrition decreases with an increasing shear zone width. For a wider shear zone, the slip between the particle layers in the failure zone decreases, thus the mechanical load on the interparticulate stress chains decreases and leads to less fatigue and failure. It can also be seen that for increasing normal stress, attrition increases for a constant shear zone width. The higher the applied normal stress, the higher the compressing load as well as the shear stress (supposing the inner friction angle remains constant, which is almost true for non-cohesive bulks), resulting in a higher amount of attrited material at the same shear strain. 


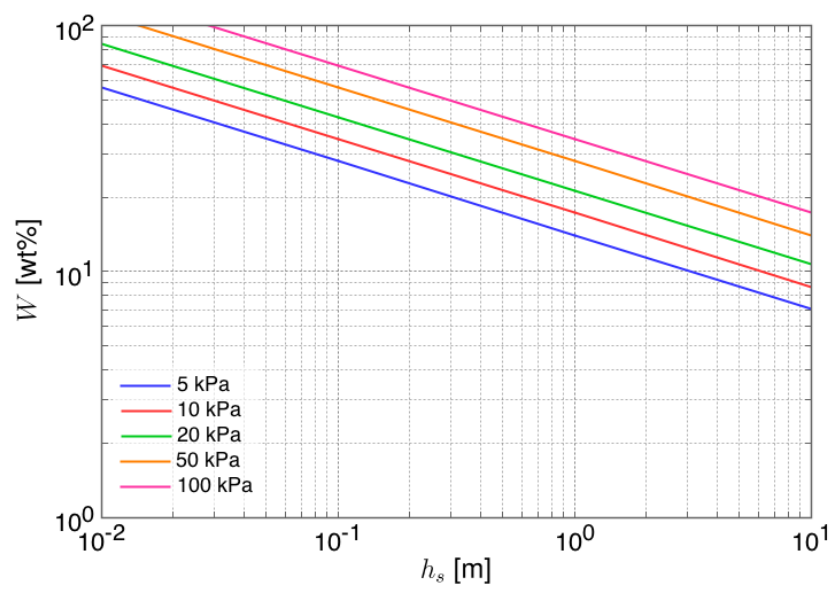

Fig. 15.

\subsection{Rheological properties}

In what follows, the results of the rheological measurements are presented and discussed. Therefore, the rheological parameters of the flow function and the critical arching dimension are introduced. These parameters are useful to characterize the flowability of a bulk and give important information for the design of bulkcontaining devices.

The flow function $f f$ is defined as the ratio of the major principal consolidation stress in the shear cell $\sigma_{\text {con }}$ and the unconfined failure strength $\sigma_{f s}$

$$
f f=\frac{\sigma_{c o n}}{\sigma_{f s}}
$$

where $\sigma_{\text {con }}$ is pre-specified by the user and $\sigma_{f s}$ is determined from measured data. The flow function comprises information about the flowability of the bulk. High values of $f f$ indicate a good flowability, while low values indicate a very cohesive bulk. The results and the classification of flow functions (stated by Jenike [29]) can be found in Fig. 16.

It should be noted that for basalt, a different batch is used from the experiments before, having a smaller mean diameter of $1.8 \mathrm{~mm}$ but the same shape factor.

From Fig. 16 it is obvious that all the materials are found to be in the easy to free flowing range. None of the bulks tends to be cohesive, since they are dry and the interparticulate adhesion force is weak for those grain sizes applied. Due to its irregular shape and high surface roughness, basalt tends to less good flowability but is still characterized as easy flowing. The best results are achieved for quartz sand and sintered bauxite. The regular shape and smooth surface of quartz sand as well as the high sphericity of sintered bauxite and the homogeneous grain size distribution of both products account for their excellent flowability.

For a plane hopper, the critical arching dimension to prevent arching of the bulk upstream of the opening can be determined with

$b_{\text {crit }}=\frac{\sigma_{\text {crit }}}{\rho_{\text {SO,crit }} g}$,

where $\sigma_{\text {crit }}$ is the critical stress and $\rho_{S O, \text { crit }}$ the critical density, both determined from the flow function measurements. It is recommended to choose an outlet length $L>3 b_{\text {crit }}$ to provide mass flow [18]. The calculated opening widths for the tested materials can be found in Fig. 17. 


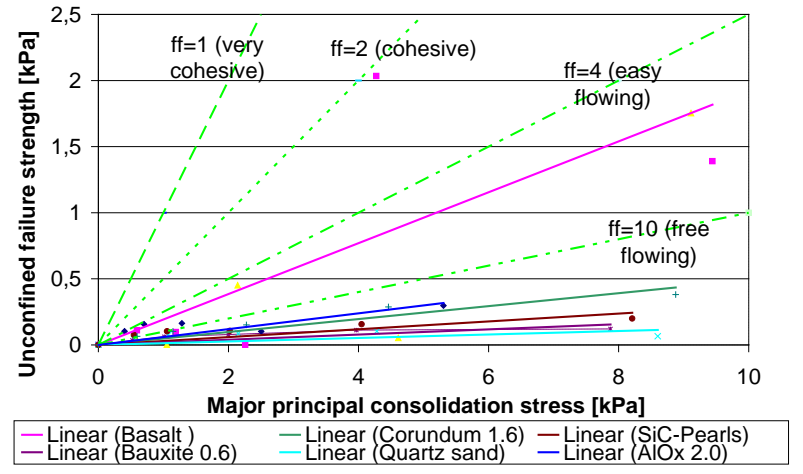

Fig. 16.

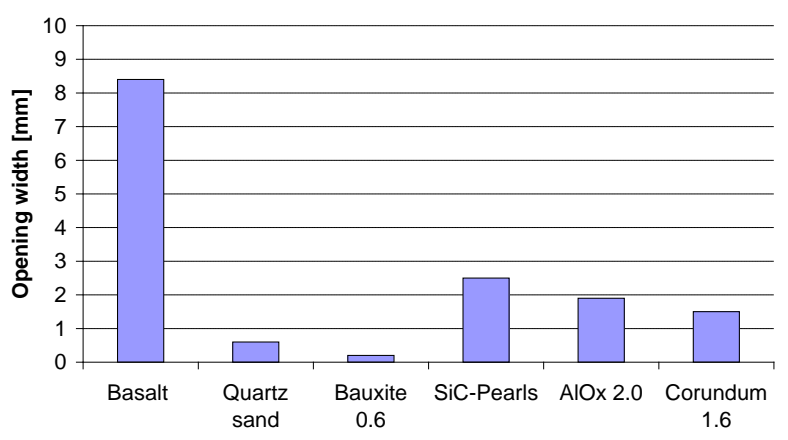

Fig. 17.

As can already be assumed from the good flowability, quartz sand and sintered bauxite require the smallest outlets. Hence, the use of basalt requires the largest opening of a hopper. However, none of the bulks requires an outlet width greater than $9 \mathrm{~mm}$. The opening dimension thus does not exceed a few particle diameters in all cases. This allows relatively small opening dimensions or flow channels in a storage system for the considered bulk products. In the case of a moving bed heat exchanger, it allows a narrow tube arrangement, resulting in a potentially compact design of the device [4]. A calculated opening width smaller than the mean grain size, like the one estimated for sintered bauxite, is not physically useful but results from the low critical stress, which corresponds to the stress that must be applied to produce plastic deformation of the bulk. Again, this indicates the extraordinary flowability of those bulks.

In section 3.2 and 3.3 of this article, it is shown that most material candidates are potentially exposed to degradation, due to either thermal shock or attrition. For an appropriate hopper design, the influence of degradation on rheological properties is considered to be essential since a change in flowability may cause a change of the critical opening width. If a hopper is designed with no respect to degradation, and the material changes its flow behaviour during operation, arching may occur even though the hopper was initially designed to prevent this. To that end, the influence of degradation on rheological properties is investigated for quartz sand and sintered bauxite. Therefore, the attrited specimens from the attrition tests are used, both expected to have reached an almost saturated state of mechanically induced attrition for given stress conditions in the shear cell.

Even though the attrited mass of quartz sand and sintered bauxite is $28 \%$ and $66 \%$, respectively, the flow function can still be characterized as free flowing for both materials (see Figure 18). Only for small consolidation stresses, a flow function $\mathrm{ff}<10$ for bauxite is determined, which is caused by the large amount of debris and the resulting widened grain size distribution. Also, the degraded particles have lost their initial spherical (bauxite) or rounded (quartz sand) shape. Both effects result in an emphatic increase of the critical arching dimension $b_{\text {crit }}$ (see Figure 19). For quartz sand, the critical opening width increases by a factor of 7, for sintered bauxite by a factor of 43 . Still, the critical arching dimension for both materials is still below $9 \mathrm{~mm}$.

The inner friction angle is a measure of the interparticulate friction of a bulk. The friction angle for untreated sintered bauxite is somewhat lower than for untreated quartz sand. The effective inner friction angle $\varphi_{i}$ as well as the bulk density $\rho$ increase marginally owing to attrition, as can be seen from Table 3 .

Table 3. Bulk density and effective internal friction angle of bauxite and sand with and without attrited material

\begin{tabular}{ccc}
\hline & $\begin{array}{c}\text { Density } \\
{\left[\mathrm{kg} / \mathrm{m}^{3}\right]}\end{array}$ & $\begin{array}{c}\text { Effective angle of } \\
\text { internal friction }\left[^{\circ}\right]\end{array}$ \\
\hline Bauxite & 2226 & 29.2 \\
Bauxite attrited & 2360 & 34.5 \\
Quartz sand & 1586 & 33.4 \\
Quartz sand attrited & 1756 & 36.0 \\
\hline
\end{tabular}

The results show that, in the case of quartz sand and sintered bauxite, even a high contribution of debris particles 
in the bulk doesn't derogate the flow behaviour significantly, but has to be considered for hopper design.

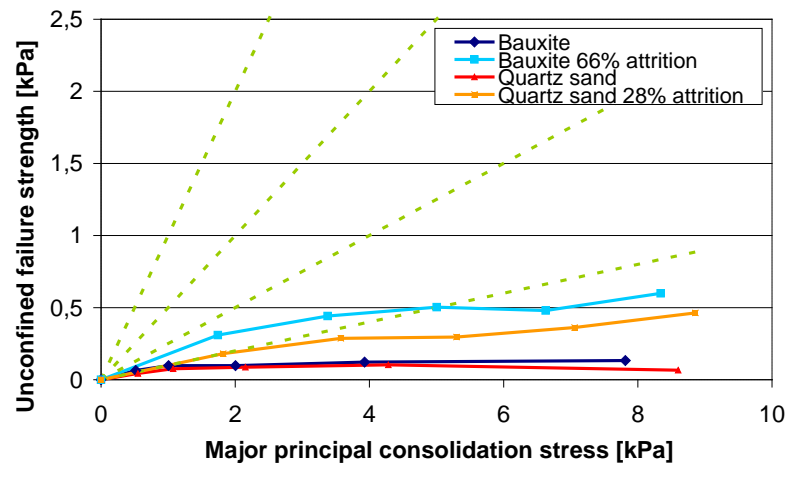

Fig. 18.

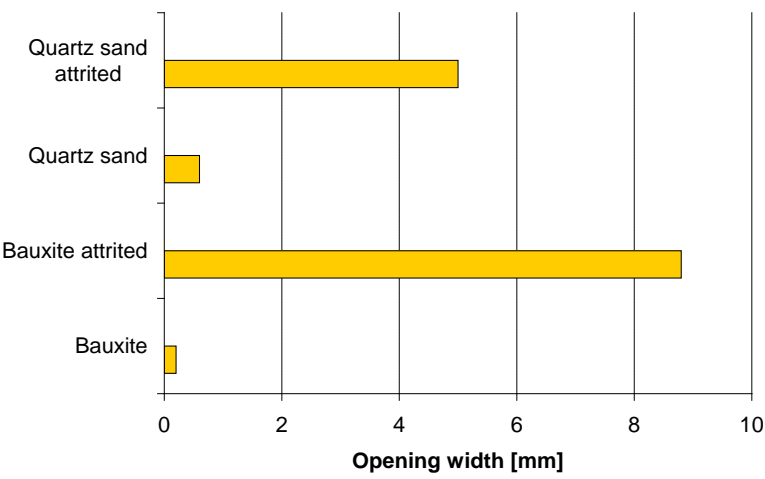

Fig. 19.

\section{Conclusions}

A variety of bulk properties have been investigated in respect to future CSP application for numerous material candidates. Besides the thermophysical properties, also selected thermomechanic, tribologic and rheologic properties have been characterized in order to estimate the bulk's behaviour in a dynamic thermal storage system.

The selected inorganic non-metallic material candidates can be classified as natural products and technical ceramics. The mean particle sizes of the investigated products range from 0.6 to $2.9 \mathrm{~mm}$.

Thermophysical properties of a bulk are determining parameters for the thermal performance of a thermal energy storage system or a moving bed heat exchanger. The thermal bulk conductivity is only marginally influenced by the molecular conductivity of the corresponding solid, thus the solid conductivity can be considered as a minor criterion for the selection of materials for CSP application. The specific heat of all the tested materials is in a narrow range around $1 \mathrm{~kJ} / \mathrm{kgK}$ in the temperature region of interest. A dependence on temperature has been identified, showing an increase of specific heat with temperature within the temperature range of interest.

The thermal shock test gives information about the degradation behaviour of the particles that would occur due to thermal cycling in the dynamic storage system. A significant difference between ceramics and natural products is detected: while all the tested ceramics exhibit a high resistance to thermal shock and show no degradation at all, the natural products show particularly strongly pronounced degradation. Materials including quartz phases are susceptible to rapid temperature changes due to the quartz inversion. To prevent these effects, a moderate cooling rate or a temperature level not including the inversion temperature is recommended. Since the latter is hard to realize in a power plant application, the former recommendation is preferred, and can be accomplished by low heat fluxes within the temperature range concerned.

Attrition is another source of degradation of the particulates. It occurs due to frictional stress in the bulk and bilateral collisions of particles. The only granular products that are completely resistant to wear are alumina grinding balls. All the other products show more or less generation of debris for a given shear strain. For most materials, a state of saturation is obtained. Quartz sand and sintered bauxite seem to exhibit the most predictable behaviour and saturate with less attrition than others. Attrition can be embanked by applying a high flow channel width to minimize the slip between the particulate layers in the shear zone. Also, a low normal wall stress would help to prevent attrition. Therefore, an optimal ratio of storage height and width has to be identified. Smooth walls, wide channels, low bulk velocities as well as mild conveying of the bulk can well prevent mechanical degradation of the particles.

Investigation of the flow behaviour shows that all the candidates can be classified as free-flowing materials, so no evidence of cohesivity is determined. Even a bulk including a significant amount of debris offers good flowability. On the other hand, degradation has a significant influence on flowability, so the possibility of a successive change in grain size distribution as well as particle shape during operation must be considered for dimensioning the bulk-carrying devices. 
Concluding, none of the candidate materials considered fulfils all the requirements perfectly, so compromises have to be made. From the economic point of view, natural stones like quartz sand or basalt are recommended. Since alumina grinding pearls are left out of a serious selection due to their price of approximately $6 € / \mathrm{kg}$, quartz sand and sintered bauxite offer the most advantages for heat transferring and storage application with respect to CSP. Quartz sand offers the lowest financial investment $(<0.1 € / \mathrm{kg}$ ) but has some drawbacks regarding thermal cycling. Bauxite (approximately $1 € / \mathrm{kg}$ ) offers excellent resistivity to thermal shock but generates a large amount of debris when it comes to attrition. All the negative effects due to these drawbacks may be minimized by applying a suitable design and operation of the devices concerned. Nevertheless, a total substitution of the system's granular inventory should be considered if the amount of attrition compromises the reliable operation of the plant. Yet, only few substitutions, which must be easily feasible and economically acceptable, should be necessary during the power plant's lifetime.

An economic evaluation of the presented technology will be the subject of future studies.

\section{Acknowledgements}

The authors would like to thank U. Kröner and Dr. N. Pfleger for specific heat measurements and M. Guemiha for grain size analysis. The work was co-funded by the German Federal Ministry for the Environment, Nature Conservation and Nuclear Safety (BMU) in the HiTExStor 1 project under contracts no. 0325119B. This financial support is gratefully acknowledged.

\section{Nomenclature}

$b \quad$ Opening width of a hopper $[\mathrm{m}]$

$c_{p} \quad$ Specific heat $[\mathrm{J} / \mathrm{kgK}]$

C $\quad$ Circumference $[\mathrm{m}]$

$d \quad$ Diameter [m]

E Young's modulus $\left[\mathrm{N} / \mathrm{m}^{2}\right]$

$f \quad$ Shape factor [-]

ff Flow function [-]

$h_{s} \quad$ Shear zone width [m]

$K_{N} \quad$ Gwyn constant [-]

l Length in direction of temperature gradient [m]

$t \quad$ Time [s]

$T \quad$ Temperature $\left[\mathrm{K},{ }^{\circ} \mathrm{C}\right]$

$V \quad$ Volume $\left[\mathrm{m}^{3}\right]$

W $\quad$ Mass fraction of attrition [-]

\section{Greek symbols}

$\alpha \quad$ Heat transfer coefficient $\left[\mathrm{W} / \mathrm{m}^{2} \mathrm{~K}\right]$

$\beta \quad$ Empirical parameter in the modified Gwyn equation [-]

$\lambda \quad$ Thermal conductivity [W/mK]

$v \quad$ Poisson's number [-]

$\rho \quad$ Density $\left[\mathrm{kg} / \mathrm{m}^{3}\right]$

$\sigma \quad$ Normal stress [N/ $\left./ \mathrm{m}^{2}\right]$ 


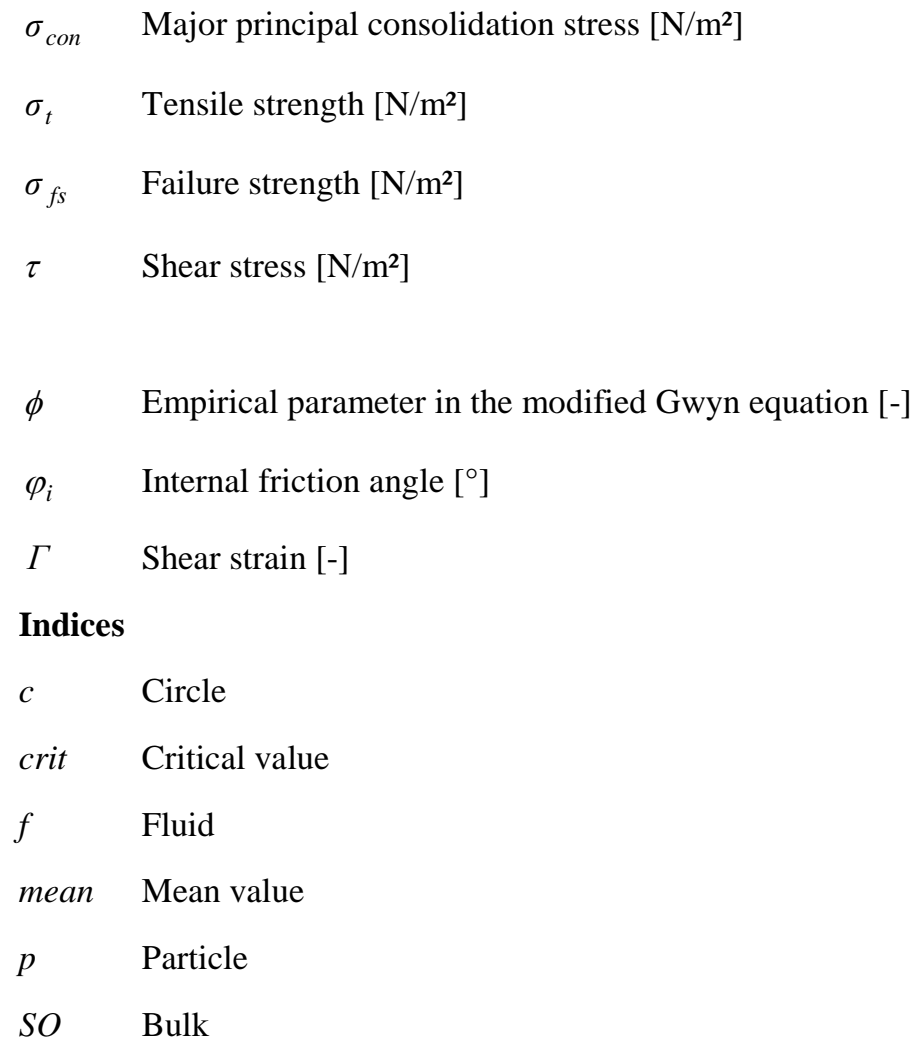

\section{Physical constant}

g Gravity, $9.81 \mathrm{~m} / \mathrm{s}^{2}$

\section{References}

[1] Z. Ma, G.C. Glatzmeier, M. Mehos. Development of solid particle Thermal Energy Storage for Concentrating Solar Power plants that use Fluidized Bed technology. Energy Procedia, Vol. 49, pp. 898907, 2014

[2] W. Wu, B. Gobereit, C. Singer, L. Amsbeck, R. Pitz-Paal. Direct absorption receivers for high temperatures. Proceedings SolarPACES 2011, Granada, Spain; September 20-23, 2011

[3] T. Baumann, C. Boura, J. Eckstein, J. Felinks, J. Göttsche, B. Hoffschmidt, S. Schmitz, S. Zunft. Air-Sand Heat Exchanger. Proceedings IRES 2011, Berlin, Germany; November 28-30, 2011

[4] T. Baumann, V. Dreißigacker, S. Zunft. Moving Bed Heat Exchanger for solar-driven steam cycles: Modeling and validation. Proceedings Innostock 2012, Lleida, Spain; May 16-19, 2012

[5] H. Salmang, H. Scholze. Keramik. Springer-Verlag Berlin Heidelberg, 2007

[6] A. Petzold. Anorganisch-nichtmetallische Werkstoffe. Deutscher Verlag für Grundstoffindustrie, 1992

[7] Brevier - Technische Keramik. Informationszentrum Technische Keramik, 1998

[8] S. H. Tscheng, A. P. Watkinson. Convective heat transfer in a rotary kiln. The Canadian Journal of Chemical Engineering, Vol. 57 No. 4, pp. 433-443, 1979

[9] J. R. Hellmann, V. S. McConnell. Characterization of spherical ceramic particles for solar thermal transfer media: A market survey. Sandia Report SAND86-1873, 1986

[10] J. R. Hellmann, M. O. Eatough, P. F. Hlava, A. R. Mahoney. Evaluation of spherical ceramic particles for solar thermal transfer media. Sandia Report SAND86-0981, 1987

[11] P. K. Falcone, J. E. Noring, C. E. Hacket. Evaluation and application of solid thermal energy carriers in a high temperature solar central receiver system. Proceedings of $17^{\text {th }}$ IECEC, Vol. 3, pp. 1498-1503, 1982 
[12] X. Py, N. Calvet, R. Olives, P. Echegut, C. Bessada. Low-cost material for sensible heat based thermal storage to be used in thermodynamic solar power plants. Proceedings of ES2009, San Francisco USA; 2009

[13] A. M. Tayeb. Use of some industrial wastes as energy storage media. Energy Conversion Management, Vol. 37 No. 2, pp. 127-133, 1996

[14] M. Dvorak, H.G. Schmid, F. Fischer. Fast Quality Control of Spray Powders. Proceedings of Int. Thermal Spray Conference (ITSC), Essen, Germany; 2002

[15]E.U. Schlünder. Wärmeübergang an bewegte Kugelschüttungen bei kurzfristigem Kontakt. Chemie Ingenieur Technik No.43, pp. 651-654, 1971

[16] VDI Heat Atlas. Springer-Verlag Berlin Heidelberg, 2006

[17] M Ghadiri, Z. Ning, S.J. Kenter, E. Puik. Attrition of granular solids in a shear cell. Chemical Engineering Science, Vol. 55, pp. 5445-5456, 2004

[18] D. Schulze. Powder and Bulk Solids - Behavior, Characterization, Storage and Flow. Springer VDI, 2006

[19]P. Zehner, E.U. Schlünder. Wärmeleitfähigkeit von Schüttungen bei mäßigen Temperaturen. Chemie Ingenieur Technik No. 14, pp. 933-941, 1970

[20]B.P. Colosky. Thermal conductivity measurements on silica. American Ceramic Soc. Bull., Vol. 31 No. 1, pp. 465, 1952

[21]F. Birch, H. Clark. The thermal conductivity of rocks and its dependence upon temperature and compostion. American Journal of Science, Vol. 238 No. 8, pp. 529, 1940

[22] L.B. Pankratz. Thermodynamic Properties of the Elements and Oxides. US Bureau of Mines Bulletin, Vol. 672, 1982

[23] M.S. Ghiorso, I.S.E. Carmichael, L.K. Moret. Inverted High-Temperature Quartz. Contributions to Mineralogy and Petrology, Vol. 68 No. 3, pp. 307-323, 1979

[24] R.E. Gibson. The influence of pressure on the high-low inversion of quartz. Journal of Physical Chemistry, Vol. 32 No. 8, pp. 1197-1205, 1928

[25] W. Schulle. Feuerfeste Werkstoffe. Deutscher Verlag für Grundstoffindustrie, 1990

[26] D.J. Gunn. Transfer of heat or mass to particles in fixed and fluidised beds. International Journal of Heat and Mass Transfer, Vol. 21 No. 4, pp. 467-476, 1978

[27] M.M. Mehed. High Temperatures-High Pressures, Vol. 15, pp. 113, 1983

[28] J. Bridgwater. Particle Breakage due to Bulk Shear. In: A.D. Salmam, M. Ghadiri, M.H. Hounslow. Handbook of Powder Technology. Vol. 12, Elsevier Science, 2007

[29]A. W. Jenike. Storage and flow of solids, Bulletin of the University of Utah, Vol. 53 No. 26, 1964 


\section{Captions for artwork and illustrations}

Fig. 1. Scheme of a solar tower power plant with a direct particle receiver, low and high temperature heat storage and integrated moving bed heat exchanger

Fig. 2. Shear cell device (left), principle of the shear cell (right)

Fig. 3. Sintered bauxite in the TCT 426 hot wire device

Fig. 4. Effective heat conductivity of various granular materials

Fig. 5. Measured and computed thermal bulk conductivity for quartz flint $\left(\mathrm{d}_{\mathrm{p} \text {,mean }}=2.0 \mathrm{~mm}\right)$ and sintered bauxite $\left(\mathrm{d}_{\mathrm{p} \text {,mean }}=0.6 \mathrm{~mm}\right)$

Fig. 6. Measured and computed thermal bulk conductivity for SiC-pearls

Fig. 7. Measured specific heat capacity for sintered bauxite and quartz sand

Fig. 8. Cumulated grain size for sintered bauxite $\left(d_{p}=0.6 \mathrm{~mm}\right)$ after $0,5,10$ and 30 cycles

Fig. 9. Cumulated grain size for alumina balls $\left(d_{p}=2.0 \mathrm{~mm}\right)$ after $0,5,10$ and 30 cycles

Fig. 10. Cumulated grain size for basalt $\left(\mathrm{d}_{\mathrm{p}}=2.9 \mathrm{~mm}\right)$ after 0 and 30 cycles

Fig. 11. Cumulated grain size for quartz sand $\left(\mathrm{d}_{\mathrm{p}}=0.8 \mathrm{~mm}\right)$ after $0,5,10$ and 30 cycles

Fig. 12. Shape factors in original and cycled condition

Fig. 13. Theoretical maximum cooling rate and the actual cooling rate for basalt and quartz sand

Fig. 14. Attrition vs. shear strain for different granular materials; solid lines represent the least square fits

Fig. 15. Attrition versus logarithmic shear zone width for a variety of applied stresses on sintered bauxite

Fig. 16. Flow functions of various bulks and classification into typical flow characteristics

Fig. 17. Arching dimensions for various bulks for a plane hopper

Fig. 18. Flow functions of various bulks and classification into typical flow characteristics

Fig. 19. Arching dimensions for various bulks for a plane hopper 


\section{Highlights}

- Thermal bulk conductivity is found to be only marginally affected by the solid's conductivity

- Ceramics entirely withstand thermal cycling

- All selected granular materials are prone to debris generation due to attrition

- generation of debris requires consideration in the design of the corresponding containment 